\title{
Political Interaction in the Process of Establishing the Regional Budget of North Sumatera Province
}

\author{
Martuama Saragi ${ }^{1}$, Tjahya Supriatna ${ }^{2}$, Sampara Lukman $^{3}$, Dety Mulyanti ${ }^{4}$ \\ 1,2,3,4 Program Doktoral Pascasarjana, Institut Pemerintahan Dalam Negeri, Indonesia \\ Email: martuama.saragih@gmail.com
}

\begin{abstract}
The purpose of this study was to analyze political interaction in the process of establishing the North Sumatera Province Regional Budget. Research using qualitative research. Research informants 13 people determined by the snowball technique. Secondary data collection uses a literature study; Primary data collection using interview and observation techniques. Data analysis in this study used descriptive analysis and triangulation. Political interaction in the process of establishing the North Sumatera Province APBD is a government communication activity that takes place between executive officials and legislative members in the context of implementing the regional financial management system and become an integral part of government management. Political interactions that occur in the context of establishing regional financial policies for one fiscal year can be either positive or negative. Positive nuance if in the process of political interaction there is a process of interaction of power that is entirely focused on the interests of the community, and it is difficult to find practices of corruption, collusion, and nepotism (KKN). Negative nuances if in the process of political interaction intertwined a process of interaction of power that is not entirely directed at the interests of the community, and indicates the existence of KKN practices. From the phenomenon of corrupt behavior involving the Governor and a number of North Sumatera Provincial legislative members in the past few years, it is clearly indicated that the process of power interaction between executive officials and legislative members could be an opportunity for KKN. That is, given the fact that power tends to be corrupt, the political interaction that takes place in the determination of the regional budget can provide opportunities for corrupt practices that harm the country and cause the people to be stiff. The new model arranged is Positive Negotiated Budget Political Model with the definition: Positive Negotiated Budget Political Model is a government communication pattern that takes place in the formulation, discussion and determination of budget policies that are entirely in the public interest and anticorruption, collusion and nepotism revealed from the motive negotiation, the proposition of negotiation and the consequences of negotiations are positive. With this definition, three dimensions of budget politics negotiation are included: (1) Dimensions of positive nuanced budget negotiation motives, (2) Dimensions of positive budget negotiation proposition, (3) Dimensions of the consequences of positive budget negotiation.
\end{abstract}

Keywords: Political Interaction, Budget, Regional Government.

\section{A. INTRODUCTION}

One of the stages of regional financial management in North Sumatera Province consisting of 25 Regencies and 8 Cities that most determines the financial performance of the region is the stage of preparing and determining the Regional Budget (APBD). From the determination of the APBD, it can be seen the policies and strategies of the North Sumatera Provincial Government in managing regional revenue sources and distributing regional expenditures to the implementation of various government policies and activities, development, public services, and community empowerment. 
It is rather difficult to formulate regional financial policies and strategies to reach certain agreements. The aforementioned difficulty arises because the agreement on regional financial policies and strategies must involve two regional government institutions, namely the Regional Government and the DPRD. Each institution must have its own authority, but in the implementation of the regional government, the system must work together. The process of the synergy of authority is certainly not free from the influence of the dynamics of political interaction between executive officials and legislative members.

With different political positions and roles, but they must synergize, there must be a process of political interaction between executive officials and legislative members. Political interaction in the process of determining the APBD is a series of government communication activities that have certain objectives. The intended purpose certainly cannot be separated from the influence of the interests of each party.

From the preliminary research activities, it was identified that the political interaction that took place in the process of establishing the North Sumatera Province Regional Budget was still not optimal. Not optimal political interactions can be either positive or negative. Positive nuance if in the process of political interaction is entirely focused on the interests of the community. In a positive nuance, it is certainly difficult to find practices of corruption, collusion, and nepotism (KKN). Negative nuances if in the process of political interaction is not entirely directed at the interests of the community, and even indicate the existence of KKN practices. KKN practices clearly not only harm the state but can directly or indirectly distress the community, especially the poor.

Meanwhile, from the phenomenon of corrupt behavior involving the Governor and a number of North Sumatera Provincial legislative members in the past few years, it is clearly indicated that the process of political interaction in the APBD determination process can indeed be an opportunity for KKN practices between executive officers and legislative members. This means that the political interaction that took place in the determination of the regional budget that was not optimal to fully represent the interests and hopes of the people of North Sumatera could occur because of the practices of KKN.

Not yet optimal political interaction in the process of establishing the North Sumatera Province Regional Budget (APBD) seems to be an interesting government communication phenomenon to be examined. Referring to this phenomenon, the purpose of this study is to analyze the political interaction in the process of determining the Regional Budget of Revenue and Expenditure in the Province of North Sumatera.

\section{B. METHOD}

The study uses qualitative research with a post-positivist paradigm. Research informants of 13 people were determined by the snowball technique. Secondary data collection from various books and documents using literature studies; primary data collection from research informants using interview and observation techniques. Data analysis 
uses Descriptive Analysis which was developed with the Analyst Triangulation Analysis Method according to the viewpoints of executive officials; from the perspective of legislative members, and from the perspective of stakeholders in North Sumatera Province.

\section{RESULT AND DISCUSSION}

\section{Political Interaction in the Process of Establishing a Revenue and Expenditure Budget in North Sumatera Province}

The political interaction that took place in the process of determining the APBD represented the interests and hopes of the people of North Sumatera seemed to be an interesting government communication phenomenon to be examined. Referring to the phenomenon, the interesting quests to be answered factually are "What is the political interaction in the process of determining the Regional Budget of Revenue and Expenditure in North Sumatera Province?" Referring to the issue of Political Interaction, Zeehandelaar (2012: 8) said that the actor using rational processes to achieve the organization's specific objectives through structure management, using bargaining and negotiation to ensure that their interests and those of the people they represent are safe. With this theoretical approach the following research results are obtained:

The use of rational processes in the determination of APBD can be interpreted as an approach to the rationalization of regional financial policies. From a descriptive analysis of the use of rational processes in the determination of the North Sumatera Province APBD the practical implications are as follows: The use of a rational process in the determination of the North Sumatera Province APBD raises certain political interaction processes that show the dynamics of government communication between executive officials and legislative members. The use of rational processes is related to the implementation of eight budget functions that include the budget as a planning tool; budget as a means of control; the budget as a fiscal policy tool; budget as a political tool; budget as a means of coordination and communication; budget as a performance appraisal tool; budget as a motivational tool; and the budget as a tool for creating public space. The use of rational processes has not been optimal in breaking down the eight functions of the budget, due to differences in bargaining position and prominence of interests between executive officials and legislative members. Therefore, a joint effort is needed to eliminate the differences in bargaining position and the prominence of interests between executive officials and legislative members, so that political interaction in the process of determining regional financial policies can take place in a positive nuance. The intended joint effort can be done by developing a budget political system that more oriented to the public interest, especially the interests of community groups who need the distribution of resources for empowerment, improving the quality of education and health services and increasing income.

Management structure in the determination of APBD can be interpreted as a hierarchy of managerial approaches in the preparation of regional budget policies. From 
the descriptive analysis of the structure management in the North Sumatera Province APBD determination process, the following practical implications are obtained: The practice of structure management in the North Sumatera Province APBD determination process is a hierarchical managerial approach to the preparation of regional budget policies consisting of long-term planning (20 years), medium-term (5 years) and shortterm (1 year). Short-term development planning is contained in the Regional Development Work Plan (RKPD) document. The RKPD is a translation of the RPJMD for a period of 1 year, with reference to the Government Work Plan (RKP) in the year concerned. The RKPD is a reference for the regions in preparing the Regional Revenue and Expenditure Budget (RAPBD). The regional head and the DPRD in determining the General Budget Policy (KUA) and the determination of the Priority and Provisional Budget Ceiling (PPAS) are based on the agreed RKPD, KUA and PPAS documents to be used as a reference in the APBD preparation process. The RKPD is a reference for the regions in preparing the RAPBD. Formally the structure management practice in the process of establishing the North Sumatera Province APBD is in accordance with the applicable laws and regulations; however, structure management practices have not been optimal for carrying out eight budget functions. The structure management practices are not yet optimal due to differences in bargaining positions and prominence of interests between executive officials and legislative members. Therefore, a joint effort is needed to optimize the practice of structural management in the process of establishing the APBD to carry out eight budget functions. The joint effort in question can be carried out by developing a budget political system that is fully directed towards the public interest, especially the public interest associated with increasing the Human Development Index.

The use of bargaining in the process of establishing the North Sumatera Province APBD can be interpreted as an approach to political communication between executive officials and legislative members. From the descriptive analysis of the use of bargaining in the process of establishing the North Sumatera Province APBD the practical implications are as follows: The use of bargaining in the process of establishing the North Sumatera Province APBD is a transactional political behavior between executive officers and legislative members carried out according to the bargaining position and specific objectives related to the regional budget allocation policy. Formally, transactional political behavior between executive officers and legislative members refers to the function of budgetary policy and is debated for and on behalf of the community, nation, and state; but actually contains certain objectives that have nothing to do with the interests of the community, the nation, and the nation. Thus the use of bargaining in the process of setting budget allocation policies can reduce the optimization of resources for implementing regional development policies. Therefore, a joint effort is needed to anticipate the use of bargaining in the process of determining the regional budget that can reduce the optimization of resources for implementing regional development policies. The joint effort in question can be carried out by developing a budgeted political 
system that is fully directed to the public interest, especially the public interest associated with improving people's welfare.

Negotiation is the process of establishing the North Sumatera Province APBD can be interpreted as transactional political behavior between the executive and the legislature carried out in accordance with the interests of each party on the policy of regional budget allocation. From a descriptive analysis of the negotiations in the North Sumatera Province APBD determination process, the following practical implications are obtained: Negotiation in the North Sumatera Province APBD determination process is a transactional political behavior between the executive and legislative parties carried out according to the interests of each party on the policy of regional budget allocation. Formally, transactional political behavior between the executive and the legislature refers to the function of the budget policy and is debated for and on behalf of the people; but actually has certain interests that have nothing to do with the interests of the people. Thus the negotiation in the process of determining the budget allocation policy can reduce the distribution of resources implementing regional development policies. Therefore, a joint effort is needed to anticipate the negotiation in the process of determining the regional budget that can reduce the distribution of resources implementing regional development policies. This joint effort can be carried out by developing a budgeted political system that is fully directed to the interests of the people, especially the interests of the people who are in dire need of distribution of resources.

\section{A New Model of Discussion of Political Interaction in the Process of Establishing the Regional Budget of North Sumatera Province}

The new model that is composed of the results of the discussion of political interactions in the process of determining the Regional Budget for Revenue and Expenditures of North Sumatera Province is as follows:

Theoretical Foundation: Political Interaction Theory: Zeehandelaar (2012: 8) says that actors use rational processes to achieve organizational specific goals through management structure, using bargaining and negotiation to ensure that their interests and the interests of those they represent are safe. Based on Zeehandelaar's theory of political interaction, a conceptual definition was prepared that Political Interaction in the process of determining the North Sumatera Province's Revenue and Expenditure Budget is a government communication process that takes place in the implementation of procedures and mechanisms for establishing the Revenue and Expenditure Budget of North Sumatera Province which is revealed from the use of rational processes, structure management, bargaining, and negotiation. From the conceptual definition, four analysis dimensions are derived: (1) Dimensions of the use of rational processes, (2) Dimensions of structure management, (3) Dimensions of bargaining use, and (4) Dimensions of negotiation.

Empirical Basis: From the description of the analysis of interviews with the 
Research Informants revealed things that can be stated as empirical facts that are dominant and become research findings (research finding). The empirical findings referred to are included in the Negotiation Dimension which refers to the following empirical:

First, the political interaction carried out with the negotiations in the ABPD's leading process basically functions to convey certain messages from one party to another. Negotiation is one of the actions of political communication carried out for a particular purpose, according to certain interests that motivate the negotiators. Although formally the negotiation aims to gather agreements for the common good; but in reality, the negotiation could be carried out for certain interests that are not relevant to the normative function of the budget. In this context, an informant revealed:

In principle, the lobbying mechanism that leads to negotiation can have both positive and negative impacts. Negative if the results of the negotiations are not in accordance with the expectations of the government and the community; and vice versa positive if the negotiations can solve problems in accordance with community expectations.

Another informant said: The purpose of the negotiations, according to my friend, is to get budgetary approval. So actually they are the ones buying and selling power ... Alaa, maak, don't be like that. If that's the case, then what can I say, the motive must be personal gain and profit for others. This advantage is wrapped with stories as if it were in the interests of the people. Alaaa mak .... this is really a negative negotiation motive not good for us.

Secondly, ideally, the proposition is based on formal rules, factual policies, common interests that refer to the objective conditions of people's lives. How the dynamics of political interaction between executive officers and legislators in explaining and defending their arguments depend on the motivations and interests that influence their arguments. In this context, an informant revealed:

Is arguing wrong? Not. It is precisely the argument of negotiation that is very important so that the person spoken to feels confident, true of what he postulated. If the proposition is based on facts, it is true, the budget is really needed, what's more, everything is delivered honestly and openly - in my opinion, does not matter. That is good. But what if the proposition they convey is actually a lie, or say far-fetched? The proposition can actually be used as a way to get something, profit or reward from the amount of the budget being negotiated. The argument for budget negotiation that is engineered to obtain something, profit or service fee from the amount of budget being negotiated is actually a KKN event. This proposition is what I call a negative budget negotiation proposition because it is done with lies, with a specific purpose that can harm the country.

Third, the logical consequence of negotiations conducted by executive officials or legislative members is that one party must be willing to understand and the same time follow the wishes or interests of the other party. For this reason, of course, there is 
compensation given by one party to another party, which insists on showing its political position. So, whatever becomes political compensation, it is certain that those who know exactly are the negotiators themselves. This political compensation is a product of political communication carried out by political actors. The impact of political compensation can be very limited, but it can also be very broad. How is the political interaction between executive officials and legislators in addressing the consequences of the negotiations - returning to the issue of political motivation and political communication that is reflected in the political interests of the political actors themselves? In this context, an informant revealed:

If the argument is based on facts, it is true, the budget is really needed for development, for the good of the people, not detrimental to the state, delivered honestly and openly - in my opinion, the consequences of the negotiations are just fine. And no need to be afraid of the KPK. In fact, in my opinion, actors who carry out budget negotiations like that deserve to get good from their service, right? But on the contrary, if the argument is not based on facts, it is not true, the budget is actually for certain purposes for certain interests that are not actually related to the good of the people, can harm the country, conveyed in certain ways - I think the consequences of nomination are you know yourself. The consequences of such negotiations must be negative.

Based on the description of empirical findings, new models were developed as a result of the development of applied theory.

New Model: The New Model is the result of the development of applied theory which is used as a theoretical foundation for the preparation of research concept definitions. The new model is the result of the application of the epistemology of Government Science which is focused on the implementation of government functions, namely the function of representation (representation) and the function of the regulation (legislation). The application of epistemology is carried out by conducting regional financial management studies which are an integral part of government management.

New Model Definition: Based on theoretical foundations and empirical findings presented, a new model that can be drawn up from the discussion of political interactions in the process of establishing the North Sumatera Provincial Budget is the New Model of the Model for Negotiating Politics with Positive nuanced Budget with the definition: Positive Negotiation Model government communication that takes place in the formulation, discussion and determination of budget policies that are fully in the public interest and anti-corruption, collusion and nepotism that are revealed from the motives of negotiation, the proposition of negotiations and the consequences of negotiations with positive nuances. With this definition, three dimensions of budget politics negotiation are covered: (1) Dimensions of positive nuanced budget negotiation motives, (2) Dimensions of positive budget negotiation proposition nuances, and (3) Dimensions of the consequences of positive nuanced budget negotiations.

Description of the New Model: Positive Negotiated Budget Political Model 
Negotiation Model is the following: Motive Positive Negotiated Budget Negotiations are internal drives of individuals and/or groups that arise from the existence of certain needs or expectations that take place in the process of actualizing budget allocation policy negotiations in the spirit of devotion, honesty and trustful and responsible institutional cooperation. The spirit of devotion can only grow and develop into an inner strength if the functions of the executive or legislative positions are accepted and implemented with the awareness that office or power is the trust mandated by the people for the people's interests. Therefore, service becomes the choice of political behavior that upholds personal and position honor; and from that set of devotion to political behavior, there are actually appropriate rewards. Honesty is the embodiment of a mental attitude that does not use lies to justify all means to achieve certain goals, and honesty requires the courage, to tell the truth.

Therefore, honesty becomes the choice of political behavior that does not justify any means to achieve certain goals; and from that honesty actually comes the glory and personal safety and position. Trustworthy and responsible institutional cooperation constitutes a network of institutional and personal cooperation between executive officers and legislative members in carrying out financial management functions formed by statutory regulations governing governance and management of state finances; and through the fabric of cooperation various policies, programs and activities of government institutions were implemented. The implementation of various policies, programs and activities of government institutions that are trustworthy and responsible can only be carried out effectively and efficiently if it is based on a spirit of devotion and honesty. Thus, the Positive Negotiated Budget Negotiation Motive includes three indicators of political interaction which include indicators of the spirit of devotion, honesty indicators and indicators of trustful and responsible institutional cooperation. Although not everyone can optimally actualize the three indicators; but awareness of the importance of the three indicators of Positive Negotiated Budget Negotiation Motives has become a good first step to launching budget politics.

The Arguments of Positive Negotiated Budget Negotiations are explanations, reasons and certain arguments that accompany budget planning that takes place in the actualized budget negotiation process with managerial descriptions and functional data of budget allocations. The managerial description includes targets and performance targets, program plans and description of activities, rules of implementation of activities. The managerial description refers to the main objectives of medium-term development planning, the basic principles of the preparation of development work plans, priorities and development goals, identification of problems in carrying out government affairs, and the direction of development policies. Functional data on budget allocation includes indicative ceilings, activity targets and targets, budget structure, and budget performance indicators. Functional data on budget allocation refers to the direction of expenditure policy and the direction of financing policy as well as the results of the search and 
discussion of specifications and standardization of goods or services and price details. The managerial description is made by reviewing strategic plan documents and other documents related to the direction of development policy. Budgeting functional data preparation is done by designing budget performance indicators and taking into account management policies and state financial responsibility. If the performance of the preparation of managerial descriptions and the performance of the preparation of functional data on budget allocations is carried out with the spirit of devotion, honesty, and cooperation of the parties that are professional and accountable, of course, the Negative Negative Budget Negotiation Proposal will be structured. Therefore, the Negative Proposition of Negotiated Budget Arguments includes three indicators of political interaction which include indicators of the spirit of devotion, indicators of honesty and indicators of teamwork that are professional and accountable. Although not everyone can optimize these three indicators; but the awareness of the importance of the three indicators of Positive Negotiated Budget Negotiations has been a good first step towards launching budget politics.

The Consequences of Positive Negotiated Budgets are dependents, consequences and certain impacts that accompany a budget planning that takes place in the budget negotiation process that is actualized by risk analysis and accountability analysis of budget performance. Risk analysis is the tracking and review of dependents, the specific effects, and impacts arising from the use of the budget that needs to be anticipated since the budget planning was approved. Risk analysis is carried out by tracing and examining everything that is expected to arise and can be detrimental to the parties, because the achievement of budget performance is not optimal and technical activities are constrained. The search and review are carried out to produce records that form the basis of a risk management approach. Budget performance accountability is the responsibility for the process and results of the use of the budget that accompany the budget planning that takes place in the budget negotiation process which is actualized by the analysis of performance accountability and analysis of budget accountability. Performance accountability analysis is the tracking and review of the process and results of the implementation of activities or work that covers various technical aspects and completion time. Analysis of performance accountability is carried out by tracing and analyzing measures of productivity, effectiveness, and efficiency in the entire set of technical implementation of activities or work according to a predetermined budget allocation policy. Budget accountability analysis is the tracking and review of the process and results of the use of activity or work budgets. Analysis of budget accountability is carried out by tracking and analyzing the forms and measures of budget accountability according to the budget allocation policy that has been previously determined. If the analysis of performance accountability and budget accountability analysis is carried out in a spirit of devotion, honesty, and synergy of the parties in a professional and accountable manner, the consequences of Negotiation on Positive nuances will be 
predicted. Thus, the Consequences of Positive Negotiated Budget includes three indicators of political interaction which include indicators of the spirit of devotion, honesty indicators and indicators of the synergy of the parties in a professional and accountable manner. Although not everyone can optimize these three indicators; however, awareness of the importance of the three indicators of the Negotiated Consequences of Positive nuanced Budgets has become a good first step towards launching budget politics.

Proposition: Based on the definition and description of the Positive Negotiated Political Budget Negotiation Model Propositions can be prepared as follows: The motives for budget negotiations are nuanced positively, the proposition of positive nuanced budget negotiations and the consequences of positive nuanced budget negotiations determine the effectiveness of political interactions in the process of determining the revenue and expenditure budget.

\section{CONSLUSION}

Political interaction in the process of establishing the North Sumatera Province APBD is a government communication activity that takes place between executive officials and legislative members in the context of implementing the regional financial management system and become an integral part of government management. With Zeehandelaar's theory of political interaction approach, the dynamics of political interaction in the process of establishing the North Sumatera Province Regional Budget shows the following conditions:

First, the use of rational processes in the process of establishing the North Sumatera Province Regional Budget (APBD) has led to a process of political interaction related to the implementation of eight budget functions that include the budget as a planning tool; budget as a means of control; the budget as a fiscal policy tool; budget as a political tool; budget as a means of coordination and communication; budget as a performance appraisal tool; budget as a motivational tool; and the budget as a tool for creating public space. The use of the rational process has not been optimal, due to differences in bargaining position (bargaining position) and the prominence of interests between executive officials and legislative members.

Second, the structure management practice in the process of establishing the North Sumatera Province APBD is a hierarchical managerial approach to the formulation of regional budget policies consisting of long-term planning (20 years), medium-term (5 years) and short-term (1 year). Short-term development planning is contained in the RKPD document. The RKPD is an elaboration of the RPJMD for a period of 1 year, with reference to the RKP in the year concerned. The RKPD is a reference for the regions in preparing the RAPBD. Formally the structure management practice in the process of determining the APBD is in accordance with statutory regulations; however, structure management practices have not been optimal for carrying out eight budget functions. 
Third, the use of bargaining in the process of determining the APBD of North Sumatera Province is a transactional political behavior between executive officials and legislative members conducted according to the bargaining position and specific objectives related to regional budget allocation policies. Formally, transactional political behavior between executive officers and legislative members refers to the function of budgetary policy and is debated for and on behalf of the community, nation, and state; but actually contains certain objectives that have nothing to do with the interests of the community, the nation, and the nation. Thus the use of bargaining in the process of setting budget allocation policies can reduce the optimization of resources for implementing regional development policies.

Fourth, the negotiation in the process of establishing the North Sumatera Province Regional Budget is a transactional political behavior between the executive and the legislature carried out in accordance with the interests of each party on the policy of regional budget allocation. Formally, transactional political behavior between the executive and the legislature refers to the function of the budget policy and is debated for and on behalf of the people; but actually has certain interests that have nothing to do with the interests of the people. Thus the negotiation in the process of determining the budget allocation policy can reduce the distribution of resources implementing regional development policies.

The new model that can be drawn up from the discussion of political interaction in the process of establishing the North Sumatera Province APBD is the New Model of the Model of Negotiating Politics with Positive nuances with the definition: Positive Political Negotiation Model fully in the public interest and anti-corruption, collusion and nepotism revealed from the motives of the negotiations, the proposition of negotiations and the consequences of negotiations with positive nuances. With this definition, three dimensions of budget politics negotiation are covered: (1) Dimensions of positive nuanced budget negotiation motives, (2) Dimensions of positive budget negotiation proposition nuances, and (3) Dimensions of the consequences of positive nuanced budget negotiations.

\section{REFERENCES}

1. Almond, G. A., \& Verba, S. (1963). The Civic Culture: Political Attitudes and Democracy in Five Nations. Princeton: Princeton University Press 
2. Bardis, D. P. (1978). Social Interaction and Social Processes dalam Jurnal International Behavioural Scientist, December (1978:7-32), in International Honor Society in Social Sciences (2014)

3. Christensen, T., \& Laegreid, P. (2002). Complex Patterns of Interaction and Influence among Political and Administrative Leaders. Stein Rokkan Centre for Social Studies, Bergen University Research Foundation.

4. Duignan, B. (2013). Political Systems, Structures and Functions. Governance: Power, Politics and Participation. Britannica Educational Publishing.

5. Easton, D. (1992). Aproaches to the Study of Politics. New York: Macmillan Publishing Company.

6. Kai Jo Fu. The Interaction of Politics and Management in Public Leadership: Measuring Public Political Skill and Assessing Its Effects. The Graduate School Florida State University Libraries

7. Zeehandelaar, D. B. (2012). The Local Politics of Education Governance: Power and Influence among School Boards, Superintendents, and Teachers' Unions. Dissertation in Faculty of the Usc Graduate School University of Southern California. 